\title{
DOSSIÊ DIGITAL CENA ANIMADA Mestres argentinos do Teatro de Animação Latino-Americano
}

\author{
DOSIER DIGITAL CENA ANIMADA \\ Maestros argentinos del Teatro de Títeres Latinoamericano
}

\author{
DIGITAL DOSSIER CENA ANIMADA \\ Argentine masters of the Latin American Puppetry
}

Mario Ferreira Piragibe (organizador) ${ }^{1}$

\begin{abstract}
RESUMO
Este dossiê digital contém uma breve descrição, seguida dos links para os registros em vídeo das mesas e conferências realizadas durante o $2^{\circ}$ CENA ANIMADA, Seminário de Estudos em Teatro de Animação do Triângulo mineiro, realizado entre os dias 10 e 13 de agosto de 2016, cujo tema foi as influências dos mestres argentinos do teatro de títeres sobre a cena bonequeira na América Latina, com especial foco sobre o teatro brasileiro.
\end{abstract}

PALAVRAS-CHAVE: Teatro de Animação; Teatro Argentino; Teatro de Bonecos.

\section{RESUMEN}

Este expediente digital contiene una breve descripción, seguida de los links a los registros en video de las mesas y conferencias realizadas durante el $2^{\circ}$ CENA ANIMADA, Seminario de Estudios en Teatro de Animación del Triángulo minero, realizado entre los días 10 y 13 de agosto de 2016, cuyo tema fue las influencias de los maestros argentinos del teatro de títeres sobre la escena del teatro de animacción en América Latina, con especial foco sobre el teatro brasileño.

PALABRAS CLAVE: Teatro Argentino; Teatro de Animación; Teatro de Títeres.

\begin{abstract}
This digital dossier contains a brief description, followed by the links to the video records of the tables and conferences held during the 2nd ANIMATED SCENE, Seminar on Studies in Animation Theater of the Minas Gerais Triangle, held between August 10 and 13, 2016, whose theme was the influence of the Argentine masters of the puppet theater on the bonequeira scene in Latin America, with special focus on the Brazilian theater.
\end{abstract}

KEYWORDS: Argentinian Theatre; Animation Theatre; Puppetry.

$$
* * *
$$

1 Professor do Curso de Teatro do IARTE UFU, com especialização e pesquisa em Teatro de Animação. Coordenador do Grupo de Estudos em Teatro de Animação (GEAC UFU), idealizador e coordenador geral do CENA ANIMADA, Festival e Seminário de Estudos em Teatro de Animação do Triângulo Mineiro. 


\section{DOSSIÊ DIGITAL CENA ANIMADA}

\section{Influências dos titiriteiros argentinas na Cena Latinoamericana de Teatro de Animação}

\section{Apresentação}

Este dossiê digital contém os links para as atividades do $2^{\circ}$ CENA ANIMADA, Seminário de Estudos em Teatro de Animação, realizado entre os dias 10 e 13 de agosto de 2016 no Curso de Teatro do campus Santa Mônica da Universidade Federal de Uberlândia. O tema do Seminário foi a influência dos mestres titiriteiros argentinos no Teatro de Animação Latinoamericano, com especial atenção ao teatro brasileiro. A presença constante de artistas argentinos na fundação e na direção de importantes companhias teatrais, bem como as memórias dos mestres itinerantes que despertaram as imaginações juvenis de futuros criadores identificam a Argentina como o berço de muitos dos principais difusores da arte do boneco na América Latina.

O seminário não conseguiu, por suas dimensões e recursos, tocar sequer a superfície de tão vasta contribuição, mas legou registros valiosos acerca de mestres importantes, e esperamos que este sirva de impulso para estudos futuros.

Os links listados abaixo conduzem para os registros em vídeo e áudio das atividades do Seminário, de acordo com seus títulos, com um registro de notas de rodapé, que podem orientar o espectador na identificação de autores, obras e eventos.

$$
* * *
$$




\section{Atividades}

1. Mesa Intercâmbios entre o Teatro de Animação argentino e brasileiro. Luiz André Cherubini, Horacio Tignenelli e Miguel Vellinho (mediação). LINK

2. Conferência A experiência do Teatro de Animação no Ensino de Ciências, por Horácio Tignanelli. LINK

3. Mesa Influências Argentinas do Teatro de Animação Brasileiro. Miguel Vellinho, Olga Romero e Valmor Nini Beltrame (mediação). LINK

4. Conferência Ana Alvarado El Teatro de Objectos e sus Hibridaciones, por Ana Alvarado. LINK

5. Conferência A Experiência do Grupo XPTO: Caminhos, Cruzamentos e Acasos Mágicos, por Osvaldo Gabrieli. LINK

6. Conferência A Influência Argentina no Teatro de Títeres Cubano, por Liliana Pérez Recio. LINK 